\title{
Testimonios de salvación: historias de conversión y cambio de vida entre creyentes evangélicos de Montevideo
}

\author{
Néstor Da Costa* \\ Valentina Pereira Arena* \\ Camila Brusoni** (1)
}

\section{Resumen}

En este trabajo se pretende mostrar e intentar categorizar los distintos testimonios de vida brindados por creyentes evangélicos conversos. En la ciudad de Montevideo se entrevistaron, a través del enfoque teórico-metodológico de la religiosidad vivida (lived religion), a 11 personas que en algún punto de su vida se convirtieron al evangelismo y que - en algún momento de la entrevista - compartieron estas historias de conversión y de-conversión, en general atravesadas por puntos de inflexión, cambios de vida y de un "antes y después" del cristianismo. Se busca también ver el potencial del acto de dar testimonio de este cambio de vida, no sólo como una herramienta para captar posibles conversos sino también como un medio por el cual se refuerzan las nuevas identidades religiosas a nivel personal y grupal en sus vidas cotidianas. Como principales resultados, se destacan, por un lado, el encontrar en las narrativas de los sujetos dos motivos principales por los cuales se produce la conversión o revinculación, así como otros elementos destacados por formar parte del proceso de reforzamiento del vínculo con su Iglesia y sus nuevas identidades religiosas. Por el otro, se encuentra que el acto de dar testimonio funciona efectivamente como un recurso positivo de validación para los creyentes.

Palabras clave: evangélicos, conversión, testimonio, religión vivida, Uruguay.

*Universidad Católica del Uruguay, Montevideo, Uruguay.

**Universidad de la República, Montevideo, Uruguay. 


\section{Testimonies of salvation: stories of conversion and change of life among evangelical believers in Montevideo}

\section{Abstract}

In this paper we seek to show and classify the different testimonies of life offered by converted evangelical believers. In the city of Montevideo, taking the theoreticalmethodological approach of lived religion, we interviewed eleven people who at some point in their lives became evangelical and who shared with us these stories of deconversion and conversion, generally crossed by points of inflection, changes of life and the "before and after" of Christianity. The investigation also sought to grasp the potential of the act of giving testimony of this change of life not only as a tool to attract possible converts but also as a means to strengthen the new religious identities (at both personal and group levels) in their daily lives. Findings suggest, on the one hand, two main reasons pointed in the narratives of the subjects, for the conversion or reconnection, as well as other elements highlighted for being part of the process of strengthening the link with their Church and their new religious identities. On the other hand, the act of witnessing is found to serve effectively as a positive resource of validation for believers.

Keywords: evangelicals, conversion, testimony, lived religion, Uruguay.

\section{Introducción}

[n las últimas décadas, el crecimiento y avance de movimientos protestantes (especialmente pentecostales) en América Latina ha sido uno de los principales temas de estudio de los investigadores de las ciencias sociales de la religión en la región. Dada la usual caracterización de Latinoamérica como adscripta al catolicismo, diversos investigadores en la década de los 1980 comenzaron a preguntarse si ésta se volvería evangélica en el futuro (Mallimaci; Giménez-Béliveau, 2007). Si bien hasta el momento el catolicismo sigue siendo la religión predominante en la región, sí podemos afirmar - 40 años después - que América Latina se ha vuelto más protestante: mientras que la Iglesia Católica ha perdido adherentes en los últimos años, las iglesias protestantes han ganado miembros. Sólo casi uno de cada diez latinoamericanos (9\%) fueron criados en iglesias protestantes, 
pero casi uno de cada cinco (19\%) ahora se describe como protestante (PRC, 2014). Este crecimiento también se refleja en la composición religiosa de Uruguay, que ha pasado de 11,2\% (INE, 2006) a 15\% (PRC, 2014) en las últimas mediciones. Estas no han sido las únicas transformaciones en el campo en el país, según señala el mismo informe: el crecimiento de los creyentes no afiliados (24\%) y el alto porcentaje de ateos (10\%) y agnósticos (3\%) en comparación con la región (PRC, 2014), merecen una mirada con detenimiento a la realidad uruguaya.

Para profundizar en términos cualitativos sobre el panorama religioso, hemos desarrollado en Montevideo (Uruguay) una investigación ${ }^{1}$ de estas características para acercarnos a la experiencia cotidiana de creyentes de distintas afiliaciones y personas sin afiliación. Con este objetivo, se realizaron entre 2015 y 2016 unas 160 entrevistas a 80 personas, de las que quedaron excluidos líderes religiosos o especialistas en la temática. De las personas entrevistadas 32 son católicas, 11 evangélicas, ocho pertenecen a cultos afro, 17 son creyentes sin iglesia y ocho son ateas. Para este trabajo, nos centraremos en las historias de vida de los 11 entrevistados evangélicos y, en particular, en algunos aspectos de los procesos de conversión que surgen de estas narrativas. Dado que solo cerca de uno de cada diez latinoamericanos (9\%) fueron criados en iglesias protestantes (PRC, 2014), nos interesa en esta oportunidad poner la mirada sobre el acercamiento de estos entrevistados a las iglesias evangélicas. Para adelantar sobre nuestros hallazgos, encontramos entre los entrevistados al menos dos tipos de testimonios de conversión, que se ven diferenciados en sus orígenes y contextos de vida.

Cabe aclarar en este punto que utilizaremos el término protestantes y evangélicos de manera indistinta (en América Latina estos términos

\footnotetext{
${ }^{1}$ Esta publicación ha sido posible a través del apoyo de beca realizado por John Templeton Foundation. Las opiniones expresadas en esta publicación son las de los autores y no reflejan necesariamente las visiones de John Templeton Foundation. El proyecto de investigación se titula «La transformación de la religión vivida en la Latinoamérica urbana: un estudio de la experiencia de la trascendencia de los latinoamericanos», siendo Gustavo Morello (Boston College) el director, Néstor Da Costa (UCU) el co-director; Catalina Romero (PUCP) la directora por el equipo de Perú, Hugo Rabbia (UCC) el director por el equipo de Argentina; y los asistentes de investigación Valentina Pereira Arena (UCU) y Camila Brusoni (UCU) por Uruguay: Lucas Gatica (UCC) y David Avilés (UCC) por Argentina; Veronique Gauthier (PUCP) y Rolando Pérez (PUCP) por Perú.
} 
"protestante" y "evangélico" se usan indistintamente²) cuando hablemos en un sentido general; haciendo solo la distinción entre protestantes históricos (p. ej., luteranos, metodistas, bautistas) y pentecostales (p. ej., Iglesia Universal del Reino de Dios, Misión Vida) cuando queramos describir a uno u otro grupo.

Asimismo, manifestar que, en las historias de vida, prestaremos especial atención a los "puntos de inflexión" de los entrevistados, entendidos estos desde la tradición interaccionista de la Escuela de Chicago, en la cual los puntos de inflexión refieren a experiencias vitales propias del ciclo de vida social y natural de las personas, que pueden implicar para estas una transición de una etapa de la vida a la otra así como una crisis vital en su experiencia (Hughes, 1971).

Además de esta introducción, el presente artículo está estructurado de la siguiente manera: primero, pasaremos a describir la composición del panorama religioso en Uruguay en términos de sus especificidades y distintivos de la región; después, haremos un recorrido histórico sobre el evangelismo en este país en base a la producción académica existente al respecto; $y$, para finalizar y entrar ya en los resultados de esta investigación en particular, describiremos la metodología y expondremos los principales hallazgos.

\section{La religión en Uruguay: composición de un panorama distintivo en Latinoamérica}

En cuanto a la composición del panorama religioso de Uruguay, según los últimos datos disponibles (PRC, 2014), el 42\% de sus habitantes se

${ }^{2}$ Las iglesias protestantes son las de misión norteamericana, que mayormente están en la Comisión de Representatividad Evangélica del Uruguay - CREU, representando aproximadamente al 6\% de la población uruguaya (Abracinskas et al., 2019). Las iglesias evangélicas son las reformadas de la línea europea. Se les llamó primero "evangélicos" (porque sólo hablaban del Evangelio) y más tarde también peyorativamente "protestantes". Las iglesias que llegaron al Río de la Plata fueron las Luteranas, Reformadas, Unidas, Valdense, Anglicana, Metodistas, Menonitas, Hermanos, Hermanos Libres, Bautistas, Discípulos de Cristo. En la década de 1970 en el Río de la Plata la teología protestante entró en diálogo con los planteos neo-ortodoxos protestantes de Europa para sistematizar lo que el movimiento de la teología de la liberación venía anunciando hacía una década (Abracinskas et al., 2019). 
identifican como católicos, un 15\% como evangélicos y menos del 6\% son de otras religiones. El $24 \%$ de la población en Uruguay se define como creyentes pero no afiliados a ninguna institución religiosa, el 10\% como ateos y un 3\% como agnósticos. Esta composición hace de Uruguay un caso atípico en América Latina y es considerado el país más secular de la región, especialmente por contar con el menor porcentaje de población católica y el mayor porcentaje de personas desafiliadas (un 37\% si sumamos ateos, agnósticos y creyentes sin religión). En la actualidad, Uruguay tiene por mucho los niveles más bajos de compromiso religioso entre los países encuestados. Menos de un tercio de los uruguayos (28\%) dicen que la religión es muy importante en sus vidas; en ningún otro país encuestado hay menos de cuatro de cada diez personas que digan esto. Relativamente pocos uruguayos dicen que rezan diariamente (29\%) o que asisten a servicios religiosos semanalmente (13\%) (PRC, 2014).

Estas cifras reflejan el resultado de diversos procesos históricos y sociales que fueron conformando este panorama, peculiar si se lo compara con el del resto del continente. Ya diversos autores han hablado de las particularidades desde lo histórico en la conformación del panorama religioso del Uruguay (Da Costa, 1999; 2009; Caetano; Geymonat; Greising; Sánchez, 2014; Caetano; Geymonat, 1997; Gigou, 2003, entre otros), siendo las principales la conformación desde sus inicios como nación de una ciudadanía con fuerte énfasis en la integración, con la laicidad como una de las herramientas que parecía asegurar dicha homogeneización; la temprana separación entre Iglesia y Estado en el año 1919; pero incluso de manera anterior distintos procesos secularizadores se llevaron a cabo en el territorio oriental. Como los principales hechos a mencionar, se destacan la secularización de los cementerios (1861); la "desconfesionalización de la educación" (1877); la ley de registro civil, en la cual éste sale de manos de la Iglesia para pasar a manos del Estado (1879); y la ley de matrimonio civil, que lo hace el único válido ante el Estado (1885).

Lo cierto es que, en la actualidad, esta matriz secular se mantiene y si bien es cierto que en el nivel de las creencias buena parte de la población del país manifiesta creer en Dios o estar adherido a alguna religión, los 
niveles de práctica (entendidos de manera tradicional) se mantienen muy bajos para todas las afiliaciones (Ferre; Gerstenblüth; Rossi, 2009).

\section{Evangélicos en Uruguay}

Al igual que lo hicimos al relatar sobre la presencia protestante en América Latina, podemos hablar de la presencia protestante en Uruguay en dos sentidos: por un lado, el protestantismo histórico y, por el otro, el crecimiento y avance de las iglesias pentecostales y neopentecostales que, si bien no crecieron en la misma medida que en otros países de América Latina, marcaron su impronta y cuentan con una presencia visible en la sociedad uruguaya.

En cuanto a los protestantes históricos en nuestro país, se dio una convergencia ecuménica progresista con las iglesias protestantes que llegaron al país con la migración de los siglos XIX y XX: las iglesias Anglicana (inglesa, escocesa), Metodista (inglesa), Evangélica Valdense (piamontesa) y Luterana (alemana, danesa o sueca) identificadas como las históricas del Río de la Plata vinculadas a las expresiones católicas progresistas (Abracinskas et al., 2019). En este sentido, señalan Caetano et al. (2014) que éstos apoyaron el proceso secularizador impulsado por el Estado a finales del siglo XIX y comienzos del siglo XX. Los protestantes en Uruguay apoyaron a los sectores liberales, aliándose a las fuerzas que promovieron la radicación de lo religioso en lo privado. Para Caetano et al. (2014), este apoyo se debía principalmente a la calidad de minoría de los protestantes en la sociedad uruguaya, por lo que el impulso secular, anticlerical y anticatólico resultaba beneficioso; hasta que el celo laicista y secularizador devino en una actitud antirreligiosa generalizada y la alianza se rompió. Desde entonces, las minorías protestantes quedaron relegadas también a la esfera de lo privado, con un rol poco influyente en la sociedad de aquella época.

Ya desde la década de los 1980 y más fuertemente en los años 1990, se asiste en el Uruguay a un arribo de corrientes pentecostales, principalmente de origen brasileño, representado inicialmente por la Iglesia Dios de Amor y posteriormente - y con peculiar énfasis - por la Iglesia Universal del Reino de Dios (IURD) (Guigou, 2006). Ya sobre finales de los 1990, esta proliferación se hizo más visible y fue una de las principales transformaciones 
del campo religioso del país (Da Costa, 1999), penetrando estos movimientos más fuertemente en los sectores de nivel socioeconómico bajo. En un comienzo, la penetración de cultos como el de la IURD ingresó por la frontera con Brasil, instalándose en la ciudad de Rivera, con un desarrollo relativamente lento en el proceso de adaptarse a la idiosincrasia uruguaya (Sotelo-Bovino, 2015). La expansión más fuerte se dio en la década del 2000: además de comenzar a adaptarse a la idiosincrasia local, las iglesias pentecostales comenzaron a transmitir su prédica en los medios masivos de comunicación uruguayos (especialmente radio y televisión), ganando mayor visibilidad a nivel de toda la población.

Esta mayor visibilidad también tuvo una respuesta en la opinión pública y los medios de comunicación del país, siendo foco de la mirada de la población uruguaya, poco habituada a este tipo de transmisiones. Ya lo observó Guigou (1993) al señalar las posturas fuera del campo de las ciencias sociales, especialmente observables en titulares de la prensa referidos a las iglesias pentecostales: "Curran con Dios", "Si cree, pague..." o "Milagros por \$20.000", son algunos de los ejemplos que muestran esta asociación de la liturgia con el dinero, con un hálito - según Guigou - de sensacionalismo y denuncia.

Respecto a la composición de la masa de creyentes pentecostales en sus primeros años, señala Guigou que fueron en su gran mayoría creyentes que pertenecían previamente a otras iglesias: "se trata en general de un público de 'segunda mano' con reminiscencias católicas, protestantes, y en particular, con antecedentes religiosos situados en el terreno de lo que se ha dado en llamar religiones afrobrasileñas" (Guigou, 1993, p. 140).

En los últimos años, se aprecia como las iglesias evangélicas (especialmente las pentecostales) buscan jugar un rol más activo en la sociedad uruguaya. Ya desde un nivel de presencia y visibilidad pública, las iglesias evangélicas han ganado terreno. Una de las principales es la IURD, con una importante impronta reflejada en la gran cantidad de templos que posee, ubicados la mayoría en zonas céntricas, en antiguas salas de cine o teatro, algunas en la principal avenida de la capital del país (Horjales et al., 2008). También se han hecho presentes en debates de cuestiones públicas y en la política partidaria de nuestro país, a destacar la inclusión de pastores 
en listas partidarias nacionales y departamentales, la presencia y visita de precandidatos presidenciales a templos evangélicos a fin de captar votantes desde un lugar de apropiación del discurso religioso y, sobre todo, la llegada de evangélicos y pastores a cargos políticos diversos, desde ediles hasta diputados nacionales. ${ }^{3}$ Cabe señalar aquí que, como mencionamos, esta tendencia se da especialmente en las iglesias pentecostales, dado que las protestantes y evangélicas históricas se han desmarcado de las posiciones conservadoras en lo público. Aunque son crecientemente minoritarias, señalan Abracinskas et al. (2019) que ellas continúan en su trabajo social, sin involucrarse en la tendencia y estrategia de participación en la política partidaria que explícitamente manifiestan los sectores pentecostales, y que incluso han dialogado y colaborado con feministas y demás sectores favorables a la legalización del aborto.

Sobre la composición demográfica de la población protestante en Uruguay, si bien no hay encuestas o estudios cuantitativos sistemáticos y representativos que ahonden en la religiosidad de los uruguayos, los datos de una encuesta realizada en el año 2009 indican que los protestantes son los que tienen niveles educativos más bajos, en comparación con los católicos y los creyentes sin afiliación (Ferre et al., 2009). El mismo trabajo arroja que también son los protestantes quienes más asisten al templo (una o más veces a la semana), es decir, son los más comprometidos con la práctica religiosa comunitaria y con su institución religiosa de referencia.

\section{La religiosidad vivida de los evangélicos en Montevideo}

\section{Sobre la investigación}

Este trabajo utiliza como metodología de base el enfoque de la religiosidad vivida propuesto originalmente por David Hall (1997) y Robert Orsi (2002). Utilizamos en este sentido los aportes de Nancy Ammerman en los estudios sobre la religiosidad vivida (Ammerman, 2014). Colocarse en la perspectiva de la religiosidad vivida como forma de abordaje al campo es una elección estratégica que nos permite devolverle el protagonismo

\footnotetext{
${ }^{3}$ Se puede ampliar en prensa: https://www.elpais.com.uy/que-pasa/evangelicos-banca.html
} 
a los sujetos religiosos, recuperando sus voces y sus historias mediante el análisis de las narrativas espirituales que los individuos construyen en los distintos ámbitos de la vida cotidiana. Implica no centrarse en cuántas veces los sujetos asisten a los servicios religiosos, pero sí focalizarse en las prácticas y conexiones que suceden en la vida diaria, en la mirada y la ética trascendente de los individuos en las cuestiones aparentemente más ordinarias de la vida.

En este sentido, la propuesta metodológica de Ammerman (2014) tiene que ver con individuar las narrativas espirituales en las historias narradas por las personas sobre sus vidas cotidianas. Desde esta lógica, se realizaron entrevistas a creyentes católicos, evangélicos, adherentes a cultos afro; también a personas que se declaran creyentes pero "sin iglesia" y ateos. El trabajo que aquí se presenta está centrado en los creyentes evangélicos. Como comentábamos al principio, este trabajo se llevó a cabo en Montevideo durante los años 2015 y 2016, y se recolectaron 11 historias de vida de personas que se consideran evangélicas (pentecostales y protestantes), de 18 a 76 años, de ambos géneros, residentes en zonas urbanas. El nivel socio económico de los entrevistados para este trabajo fue separado en dos categorías: nivel medio-alto y bajo.

Con cada uno de los entrevistados se realizaron dos encuentros en donde se les preguntó acerca de su historia y de cómo lo religioso o espiritual ha estado presente o no. Se les preguntó además acerca de sus rutinas cotidianas en su hogar, su trabajo, en su tiempo libre; en la relación con su familia y los amigos, y estuvimos atentos a cómo y cuándo las narrativas espirituales iban surgiendo en el relato de lo cotidiano.

\section{Sobre el perfil de los evangélicos entrevistados}

En términos de adscripción religiosa, de los 11 creyentes evangélicos entrevistados, seis son pentecostales y cinco protestantes históricos - una luterana, dos miembros de la Iglesia Cristiana Evangélica Espronceda (Hermanos Libres) y dos miembros de la Iglesia de los Nazarenos. Fueron cinco entrevistadas mujeres y seis hombres, siete de nivel socioeconómico bajo y cuatro de nivel socioeconómico medio/alto. La muestra de este estudio (para todas las afiliaciones entrevistadas) fue intencional e intentamos sobre- 
representar a los niveles socioeconómicos más bajos y, en particular para el mundo evangélico cristiano, contar con entrevistados tanto pentecostales como protestantes históricos. Cabe aclarar en este punto que, dada la naturaleza del estudio, no pretendemos generalizar los hallazgos a partir de estos casos que, aunque estudiados en profundidad, no son numéricamente representativos. La intención en este sentido es más bien ensayar posibles puntos de encuentro y reflexiones sobre los cambios de vida y conversiones evangélicas en nuestro país.

En un trabajo publicado recientemente (Da Costa; Pereira Arena; Brusoni, 2019) realizamos una primera caracterización del perfil de los evangélicos de este estudio. Como principal cualidad, se destaca el alto nivel de adhesión hacia la institución religiosa para los afiliados de todos los niveles socioeconómicos. En este sentido, los relatos sobre el vínculo con su iglesia forman parte central de su narrativa espiritual, destacando la asistencia a los servicios, la relación con la comunidad de creyentes y el vínculo cercano con el pastor de su templo. Una de las grandes diferencias con los católicos entrevistados del estudio reside en la manifestación de su religiosidad y espiritualidad en sintonía con las creencias institucionales.

En general, podemos decir que en los relatos no surgen grandes cuestionamientos hacia los mandatos de sus iglesias e, incluso, en algunos casos aparece la crítica hacia otras religiones como parte del refuerzo de las creencias institucionales que les son propias. Discursivamente, se destaca la utilización de un "nosotros" para hablar de las creencias propias, así como una mayor referencia a la Biblia como modelo para establecer pautas, dos puntos en los que se distancian de los entrevistados católicos de nuestro estudio.

Como otro punto a destacar, los protestantes entrevistados hacen hincapié en la importancia que tiene para ellos la relación entre las creencias y su vida cotidiana. En sus narrativas cotidianas, su fe está presente en todo momento: en el encuentro con el otro, en su trabajo, en la relación con la naturaleza, por citar algunos ejemplos, siendo una guía y compañía permanente que ayuda a desarrollarse mejor como persona. También cabe destacar que, así como sucede con los católicos, entre los evangélicos de sectores más desfavorecidos y especialmente para los pentecostales, se 
asocia la participación en servicios religiosos o la asistencia a determinados templos no sólo como un espacio de desarrollo de creencias y prácticas religiosas y espirituales, sino también como la búsqueda de acceso a una especie de red de contención que funciona como proveedora de recursos básicos, servicios etc. Eso confirma lo planteado por Mallimaci y GiménezBéliveau (2007), que los grupos evangélicos pentecostales proponen a sus fieles una intensa vida en comunidad que, rápidamente, se convierte en una red de apoyo material y simbólico frente a situaciones de desamparo.

\section{Testimonios de salvación: sobre las experiencias de conversión y cambio de vida}

Lo primero que cabe señalar, tal como se explicita en nuestro trabajo anterior (Da Costa; Pereira Arena; Brusoni, 2019) es que las personas evangélicas entrevistadas - de diferentes corrientes - cuentan con un nivel de adhesión y práctica institucional alto. De las 11 que forman parte de la muestra, diez asisten con una frecuencia al menos semanal a sus iglesias $u$ otros espacios de fe institucionales y en la mayoría de los casos la frecuencia es aún mayor (dos o tres veces por semana, incluso hay quienes asisten casi diariamente).

Celeste, la única entrevistada que manifestó que ya no asiste regularmente a espacios institucionalizados, se alejó luego del fallecimiento de su hijo - quien era muy practicante. La entrevistada manifestó sentir que las personas referentes de la iglesia no estuvieron para acompañarla como ella esperaba, por lo que tomó distanciamiento. Sin embargo, y a pesar de no asistir actualmente al templo, Celeste ora diariamente y mantiene muchas prácticas que coinciden con aquellas de los demás entrevistados. Es decir, en el único caso en que una entrevistada se manifiesta alejada de la Iglesia en tanto espacio de práctica de la fe, aun así manifiesta su cercanía diaria a Dios y a Jesús a través de sus prácticas y reflexiones, sin duda muy mediadas por la mirada evangélica.

Respecto al acercamiento de los entrevistados a su iglesia y denominación religiosa actual, nos encontramos con al menos tres diferentes situaciones relacionadas a su punto de partida religioso, que detallamos a continuación. En primer lugar, están quienes provienen de familia evangélica, con un 
fuerte grado de participación y siguen manteniendo - en mayor o menor medida - su vínculo con la misma iglesia, sin grandes cambios a nivel de su fe. Llamaremos a este grupo "protestantes de origen".

En segundo lugar, están quienes en el pasado tuvieron algún tipo de vínculo con iglesias o comunidades evangélicas, pero se trataba de un vínculo débil o sin demasiada relevancia que luego o bien emigraron hacia una nueva iglesia o vivieron algún acontecimiento que los lleva a acercarse a la institución con mayor fuerza y a participar frecuentemente. Estos son casos en los cuales, si bien no se puede hablar de conversión, sí existe un grado de alternancia que viene de la mano de un reforzamiento de su fe o sus creencias. De aquí en más, el grupo de los "protestantes re-vinculados".

Por último, está el grupo de "conversos" propiamente, conformado por personas que no procedían del mundo evangélico, pero pasaron por un proceso, donde ser evangélicos es parte de su nueva identidad religiosa. En estos casos no existe una característica principal a nivel de origen: algunos tuvieron una socialización católica débil, otros vienen de ámbitos familiares sin una definición religiosa clara, otros son ex no creyentes.

En el primer caso, entre los protestantes de origen encontramos a Marcela, que desde que nació participa de la Iglesia de los Hermanos Libres y particularmente asiste a la comunidad Espronceda con frecuencia semanal. Manifiesta su comodidad en esa comunidad porque se trata de un espacio de mayor igualdad dentro de su iglesia, ya que allí las mujeres pueden dar testimonio y hay mayor lugar para que los niños practiquen - eso la diferencia de otras iglesias de Hermanos Libres. Marcela es de nivel socioeconómico (NSE) medio alto, estudiante universitaria y también manifiesta cómo, a medida que ha ido creciendo, ha valorado también sus vínculos por fuera de los espacios evangélicos, en los que su paso por la universidad también tuvo que ver.

En un caso similar, dentro de las personas evangélicas de origen, está Sabrina. El caso de ella es distinto al de Marcela porque, si bien desde que nació y a través de su familia formó parte de la Iglesia Luterana - de la cual participó frecuentemente a lo largo de su vida -, durante la entrevista comenta que, con un grupo de gente del que participa, empezó a acercarse a la Iglesia Metodista, en principio para utilizar el espacio físico, 
por algunos inconvenientes que tuvieron con la Iglesia Luterana que hizo que se alejaran. Al momento de la entrevista, el conflicto parecía incipiente porque ella tampoco ahonda en el tema, además de que se presenta y se sigue definiendo en líneas generales como luterana.

Uno de los datos interesantes para el análisis de esta subcategoría, dentro de las personas creyentes evangélicas, es que ambas entrevistadas son de corrientes protestantes históricas y NSE medio-alto. Esta observación tiene sentido si la analizamos en el marco de los procesos que los movimientos cristianos tuvieron a lo largo del continente y también en nuestro país. En general, las iglesias pentecostales incorporaron a sus filas muchos fieles en las últimas décadas - particularmente en los últimos años - pero sobre todo en los sectores populares.

Por otro lado, en el grupo de los protestantes revinculados, contamos con tres casos: los tres son de nivel socioeconómico bajo, dos son de corrientes pentecostales y uno es protestante histórico. Al partir de esta segunda categoría, encontramos en los relatos de las personas entrevistadas situaciones muy concretas y de gran impacto que resultaron fundamentales al momento volver a acercarse a la iglesia. Esto se manifiesta en términos de "puntos de inflexión" en la vida de los entrevistados. Sol, una de nuestras entrevistadas revinculadas, nunca le había dado importancia cuando asistía a la iglesia hasta que una amiga de su hermano la invitó:

Me invitaron y dijimos "vamos", fui un miércoles y ahí fue cuando empecé a creer en Dios. Fue pisar el portón y me puse a llorar, pero lloraba y no entendía por qué lloraba. Lloraba, Iloraba y lloraba. Y ese miércoles, que hoy en día no se hace, ese día especial, era un día de liberación (Sol, entrevistada evangélica).

Este tipo de testimonios es muy frecuente; algunos los veremos más adelante, en los que los entrevistados perciben una especie de fuerza espiritual que funciona como señal para acercarse a las iglesias.

Por otra parte, Isidoro cuenta que siempre estuvo buscando un espacio religioso y que se acercó cuando llegó a su barrio una campaña evangélica y comenzó a participar activamente. Luego, tuvo otra etapa en la que su participación fue baja, pero manifiesta que siempre se sintió evangélico, pone de ejemplo que bautizó a sus hijas en ese momento que estaba 
alejado. Su segundo acercamiento se dio a través de un inconveniente que vivió con unos jóvenes que estaban celebrando Halloween, que entendió como una señal para volver periódicamente a la iglesia. A partir de allí, y de un diálogo que tuvo con su hija luego de esa instancia, volvió a participar activamente. Por lo tanto, en su vida hubo dos puntos de inflexión que lo hicieron acercarse a la iglesia, uno primero en el que Iglesia lo buscó a él a través de una campaña y el segundo cuando él se acercó por una situación que consideró decisiva para retornar.

Asimismo, Celeste también se acercó a la iglesia cuando uno de sus hijos a los cinco años enfermó del corazón y eso coincidió con que la Iglesia se acercó a su barrio. Ella narra los dos sucesos en paralelo, como causa y consecuencia de su acercamiento a la iglesia: "me gustaba porque era muy hermanos, se trataba de hermanos y la amistad de las familias, la palabra de Dios que siempre me gustó, pero me gustaba la amistad de la familia..." (Celeste, entrevistada evangélica). Luego se alejó años después por la pérdida de su hijo, tal como se detalló anteriormente, justamente porque no siente ese apoyo de la comunidad de la iglesia que sintió en un inicio.

El relato de Celeste sirve como ejemplo de lo que Míguez (2000) Ilama estructura de plausibilidad ${ }^{4}$ de las iglesias pentecostales y que aparece a lo largo del testimonio de gran parte de las y los entrevistados que pertenecen a este tipo de iglesias. Esto sucede cuando las iglesias tienen una forma de estructura que facilita la llegada de nuevos integrantes, que también tiene que ver con esa idea de la iglesia acercándose al sujeto y su entorno - que veremos más adelante -, lo que permite que el creyente se incorpore de lleno en la lógica institucional desde varios puntos de vista: en sus prácticas, vida cotidiana, espiritualidad etc. En palabras del autor:

"El concepto de "estructura de plausibilidad" es original de Peter Berger (1969) en El dosel
sagrado, en términos de la necesidad del mundo de una base social con la que continuar
existiendo como un mundo real. Daniel Míguez (2000) habla de estructura de plausibilidad
al referirse a los elementos que permitirán que el individuo acepte las nuevas definiciones
de realidad propias de su nueva identidad. Se sobreentiende que toma la noción de Berger
dado que los elementos que señala Míguez son las nuevas definiciones de realidad y un
grupo social portador de esas definiciones con el que el individuo puede interactuar,
ofreciendo así una base social con la que continuar existiendo dentro de una cierta realidad. 
Generalmente, quién se acerca a una congregación pentecostal será inmediatamente llamado 'hermano/a', recibirá la visita del pastor y será integrado a grupos locales donde podrá encontrar rápidamente referentes que actúen como mediadores entre el individuo en proceso de conversión y el grupo. Esto en los casos en que no haya sido ya un converso quién introdujo inicialmente al individuo en el grupo (Míguez, 2000).

Estos son aspectos muy relevantes y de clara importancia en las vivencias de los evangélicos entrevistados que se acercaron a este tipo de iglesias más tarde en su vida: la cercanía con referentes religiosos que inmediatamente los incorporan a los espacios de participación y que empatizan desde un lugar muy cercano con sus vivencias y problemas, además de ofrecerles una mediación o guía en su vínculo con Dios. Esto se distancia mucho de la forma de vincularse con las instituciones que vivencian los entrevistados católicos dentro de esta misma muestra.

El caso de Celeste también nos da pie para hablar de otro aspecto que surge en el relato de gran parte de los entrevistados de la muestra de evangélicos, en que la espiritualidad y salud aparecen como aspectos muy entrelazados: los estados delicados de salud, los testimonios de curación en iglesias pentecostales, por ejemplo, son recurrentes en los testimonios de los entrevistados, tal como veremos más adelante.

Como ya mencionamos, esa noción de la Iglesia acercándose al individuo aparece también frecuentemente en los discursos de los entrevistados evangélicos que profundizan su fe a través de estas vivencias, así como varios de quienes son totalmente conversos. Cuentan que comenzaron a participar luego de campañas propias de las iglesias en las que estas se acercan a los barrios, así como a través de conocidos que los invitan a participar. Esta observación está en sintonía con los resultados de la investigación realizada por el Pew Research Center en 2014, los cuales indican que, en América Latina, particularmente aquellos que cambiaron la Iglesia Católica por iglesias evangélicas, manifiestan que lo hicieron porque la nueva iglesia se acercó a ellos (PRC, 2014). A partir del análisis de los relatos, podemos ir un poco más allá, complejizar este dato, para el caso de quienes formaron parte de nuestra muestra, y comprender el sentido de esta afirmación. 
En esa línea, gran parte de los conversos también cuentan en sus relatos momentos que fueron puntos de inflexión en su trayectoria de vida y que tuvieron que ver con su conversión, con su acercamiento a la iglesia evangélica de la que participan. En el grupo de los "conversos" están más de la mitad de los entrevistados evangélicos de la muestra. Tal como se detalló anteriormente, vienen de procesos religiosos débiles, de familias no practicantes e incluso con prácticas religiosas diversas o sincréticas. En este grupo hay dos personas de NSE medio-alto: una metodista (Mirta) y otro actualmente pertenece a la Iglesia del Nazareno (Felipe), pero que se acercó al mundo evangélico a través de una iglesia pentecostal; tres personas de NSE bajo de iglesias pentecostales (José, Fabián y Ernesto) y uno de Hermanos Libres (Martín).

Tal como comentamos anteriormente, en el relato de la mayoría de los conversos aparece una referencia clara a determinados puntos de inflexión - tal como sucedía en el caso de quienes, si bien no son conversos, comenzaron a participar de espacios institucionales con mayor compromiso. Esos puntos de inflexión tienen que ver con diversos motivos, según los entrevistados, pero que comparten algunos aspectos generales en los que coinciden la gran mayoría, por ejemplo: cuestiones vinculadas a la salud, como ya se dijo anteriormente, en que reciben algún tipo de señal o prueba por parte de Dios, muchas veces en el marco de algún ritual institucional. Hay muchos testimonios entre estos entrevistados sobre personas que fueron curadas de Sida, enfermos de cáncer, personas que no podían caminar. Incluso desde un lugar de testigos, el presenciar estas sanaciones es vivido por ellos como un punto de inflexión vital:

(...) fue en una campaña de Annacondia (...) un evangelista argentino (...) y ahí yo llevé a mi madre (...) que cuando entró estaban orando y todo eso, (...) tenía unos escalones todo para subir para las gradas ahí. Ella estaba subiendo los escalones corriendo. Yo la miraba, no podía creer. No podía ni caminar y subió esos escalones corriendo, digo: - iy esto? - iGloria a Dios! gritaba, pero yo no sabía que era... y resulta que Dios era que la estaba ayudando. Y ta ahí los dos recibimos al Señor y de ahí después sí ya empezamos a congregarnos... todo eso (Ernesto, entrevistado evangélico). 
Por otro lado, hay quienes sintieron un llamado de Dios con señales vinculadas a otro tipo de experiencias - estas se dan muchas veces en sueños, como en el caso de Fabián que soñó con el exnovio de su esposa antes de que ella le hablara de él:

Mi primera experiencia fue esa: que Dios me mostrara en el sueño un nombre que yo no conocía. Me impactó cuando yo hablé con Manuela y ella me dijo quién era. Después al tiempo estábamos con Manuela y ese Francisco viene y se me presenta y me habla. Me dice que no sabía, que algo lo estaba inquietando a él a decirnos que hacemos una muy buena pareja. Eso lo tomamos nosotros como de parte de Dios, que él viniera a hablar con nosotros y que fuera justamente el exnovio de ella, el que venía a decirnos algo de parte de Dios (Fabián, entrevistado evangélico).

Retomando a Míguez, en estos testimonios se puede observar experiencias en las que los entrevistados vivencian en su propio cuerpo aquello que los pastores les hacen llegar a través de la palabra, que la dota de una enorme credibilidad y asegura un camino de éxito si se incorporan a estos espacios (Míguez, 2000).

Otro aspecto importante a señalar - tanto en los conversos como en los revinculados - es respeto a los mandatos y su predicación a través del testimonio, que tienen incorporados a sus discursos. Esta incorporación resulta, en parte, del proceso bien logrado de las iglesias pentecostales para nuclear a un entorno de fieles que validan sus discursos, dando posibilidad a los propios creyentes de brindar testimonio, otorgándoles así cierto reconocimiento y permitiendo la validación entre pares:

Los testimonios de curación son brindados por los mismos fieles durante el proceso ceremonial, siendo irradiados por todas las audiciones que tienen en el dial. Aquellas personas que se acercan a la Iglesia poseen, por tanto, una garantía de que su pedido será escuchado por el espíritu santo, vía la experiencia de los testificantes, de "los otros". A su vez esta garantía se extiende al vehículo material: el dinero "... no se tira a la calle" porque colabora con la sanidad, con la solución a los problemas como obviamente demuestra el sinnúmero de testimonios dados por fieles y simpatizantes (Guigou, 1993, p. 141). 
Como dijimos desde el comienzo, los evangélicos son, dentro de diferentes tipos de creyentes de nuestra muestra, de los que tienen vínculos más estrechos con la institución religiosa. Esto es particularmente importante, dado que, desde esta, se les impone cierto tipo de prácticas con las que tienen que cumplir y que ellos, a diferencia de los católicos, por ejemplo, dejan permanentemente en claro que las respetan y lo predican, como la prohibición de relaciones sexuales prematrimoniales, no beber, no fumar etc.:

Yo creo que el cristiano, la persona que sigue el evangelio se tiene que resistir a muchas cosas, resistirse a pasiones desenfrenadas, a un vicio. Hay jóvenes que quieren salir, ir al baile a tener noches de lujuria y desenfrenadas y hay jóvenes que no... (Fabián, entrevistado evangélico).

La mayoría de ellos narra un antes y un después de la presencia de la experiencia religiosa en su vida, respecto a este tipo de aspectos: muchos indican que antes fumaban o no, otros que antes eran cercanos a personas con adicciones. Como Sol, quien indica que en los momentos en que se distanció de la iglesia estaba de novia con un adicto a la pasta base. Son reflexiones que surgen permanentemente en el testimonio de todos los entrevistados, tanto con relación a ellos mismos, como a familiares o amigos. Señalan ese cambio como algo que demuestra a Dios actuando en ellos, que les dio la fuerza para eso, aunque también evidentemente funciona como prueba de comportamiento, necesaria para formar parte de la iglesia.

Por ejemplo, el caso de Isidoro: "Yo en dos Santa Cena distintas en mi vida dejé de fumar. No sé si fumaste alguna vez, verás que es complicado dejar el cigarrillo, y en dos Santa Cena dejé de fumar. Todo va en el compromiso que tiene cada uno" (Isidoro, entrevistado evangélico). Por otro lado, está el caso de José, que se convirtió a evangélico mientras estuvo en la cárcel, a través de su testimonio narra cómo, una vez que salió, le costó mantenerse dentro de lo que sus creencias le decían lo correcto, pero también narra cómo la iglesia y la pastora lo ayudaron en esa situación:

Para mí es importante porque yo ahí como que renuevo mis fuerzas y limpio mi mente de cosas malas. Y porque yo lo pasé, apenas salí de la cárcel yo la pasé muy mal, no dormía, fumaba mucho, estaba re mal de los nervios y se me ocurrían cosas malas. Y bueno, ahí me dediqué más firme, empecé a estar acá con la pastora que me conoce... (José, entrevistado evangélico). 
Esto está muy vinculado a lo que Míguez denomina actos de compromiso, en donde el nuevo creyente otorga determinadas pruebas para pasar de ser miembro a prueba a miembro pleno (Míguez, 2000). Si bien no podemos asegurar que esto sea así, dado que no se explicita en los relatos de los entrevistados, se trata de una lectura válida para echar luz sobre la importancia otorgada a este tipo de cambios de vida.

Finalmente, destacaremos brevemente otro elemento que entendemos importante para dar cuenta de las características de la conversión o cambio de vida en los creyentes evangélicos. Además de los aspectos vinculados a ciertos comportamientos que denotan ese cambio, existe algo recurrente a nivel discursivo por parte de varios de los entrevistados: la alusión directa y crítica a otras religiones - particularmente a católicos y umbandistas - como formas incorrectas de contacto o mediación con Dios.

Estas críticas surgen por experiencias pasadas, por ejemplo, quienes vienen de socialización católica tienden a criticar la visión castigadora de Dios que tiene el catolicismo, a su entender, y que se diferencia de lo que predica el evangelio: "Dios es amor". También señalan otras diferencias como la adoración a imágenes en católicos y la realización de brujerías y macumbas por parte de umbandistas. Esto también se condice con lo señalado por Míguez (2000), en el sentido de que no sólo los puntos de tensión (de inflexión, en nuestras palabras) son relevantes, sino que una cierta disconformidad con su identidad religiosa tradicional suele ser también motor para el cambio. Destaca en este punto lo dicho por Berger y Luckmann (1986) en tanto que en toda organización dedicada a la conversión existe un mecanismo de rechazo de la perspectiva anterior, sumado a procedimientos que instituyen la nueva perspectiva de realidad en el individuo.

En este sentido, el distanciamiento de otras formas de religiosidad que muchas veces pueden verse asociadas a las prácticas propias - oficia, a su vez, como reforzador del vínculo con el colectivo. 


\section{Conclusiones}

Podemos decir que la alternación religiosa (Míguez, 2000) implica usualmente la existencia de "estructuras de plausibilidad" (Berger, 1969) que hacen creíble para el individuo el cambio, y cuyas bases son provistas en general por grupos de referencia encargados a tales fines. En el caso de las alternaciones religiosas de los entrevistados evangélicos de este estudio (tanto de aquellos provenientes del mundo evangélico, como de los típicamente "conversos"), podemos observar que los pastores y los otros miembros de la comunidad resultaron fundamentales para establecer dichas estructuras básicas, incluso para resaltar la importancia del "cambio de vida". También cabe resaltar otros elementos que parecen haber contribuido a los creyentes de este estudio con el acercamiento y reforzamiento del vínculo con sus iglesias. En primer lugar, la importancia dada en sus narrativas a la percepción de una especie de fuerza espiritual que funciona como señal para acercarse a la Iglesia. Las señales como concepto forman parte de las palabras recurrentes en varias de las historias de los sujetos participantes al referirse al momento del acercamiento o de la revinculación. En segundo lugar, el lugar que toman el cuerpo y la experiencia corporal en los rituales, especialmente aquellos vinculados a la sanación, también forma parte importante del proceso de vinculación y sirve como "prueba" y legitimación de la Iglesia y sus líderes.

Respecto a los testimonios de salvación, encontramos en estas entrevistas testimonios de dos tipos, principalmente. Los primeros, vinculados a puntos de inflexión o tensión que fueron claves para buscar o "dejarse encontrar" por las iglesias evangélicas y todo el universo de significados que estas les proveen. Entre nuestros entrevistados, los principales puntos de tensión tenían que ver con problemas de salud (ajenos o propios), muerte de alguien cercano, problemas de adicciones o experiencias de vivencias en situación de ilegalidad. Estos testimonios fueron brindados por los entrevistados de nivel socioeconómico bajo.

El segundo tipo de testimonios está fundamentalmente vinculado a una ruptura con una identidad religiosa anterior por no proveer esta los elementos espirituales y simbólicos que el individuo manifiesta necesitar en su vida. 
Cabe aclarar que para el resto de los entrevistados de esta investigación, tanto los puntos de inflexión vitales como la disconformidad con la identidad religiosa previa fueron factores claves para generar una alternación religiosa de algún tipo. Lo que encontramos como distintivo entre los evangélicos y el porqué de su afiliación a estas iglesias en particular son dos cuestiones fundamentales. En el caso de los entrevistados de nivel socioeconómico bajo que presentaron el primer tipo de testimonio, fue elemental la proximidad de iglesias pentecostales en su entorno vital, sumado a una capacidad discursiva de estas iglesias y sus comunidades de adaptarse a las realidades populares, hecho que también ha sido expuesto previamente en la teoría presentada. En el caso de los entrevistados disconformes con su identidad anterior, el pasaje previo por iglesias protestantes o el contacto realizado a través de alguna persona cercana a su entorno, pareció ser un factor más decisivo para su conversión.

Respecto al acto de dar testimonio, se observa en los entrevistados la incorporación en sus discursos de esta práctica. Esta integración parece en parte el resultado de un proceso bien logrado de las iglesias pentecostales para nuclear a un entorno de fieles que validan sus discursos, dando posibilidad a los propios creyentes de brindar el relato de su experiencia como útil para los otros; al mismo tiempo que les otorgan reconocimiento y permiten la validación entre pares.

Para finalizar, otro elemento emergente e interesante para abordar en futuros trabajos es la fuerza que tiene en muchos de los creyentes evangélicos los mandatos que se predican desde sus iglesias, particularmente en el caso de los pentecostales. Algunos de estos aspectos son el respeto a la prohibición de las relaciones sexuales prematrimoniales y la prohibición del consumo de sustancias psicoactivas y su estigmatización, elementos que resultan también en una prueba de pertenencia y expresión de su espiritualidad. Por otra parte, existen también otras referencias que son recurrentes en las entrevistas - que por cuestiones de espacio han quedado fuera del análisis de este trabajo - como las alusiones desde una perspectiva conservadora y regresiva hacia las formas no heteroconformes de relaciones sexuales, al matrimonio igualitario, así como hacia la legalización y la práctica del aborto; que se conjugan con una reproducción a nivel discursivo de nociones de 
identidades y expresiones de género tradicionales. La autonomía de los sujetos creyentes en relación a los discursos de este tipo provistos muchas veces por sus instituciones de referencia también es una cuestión interesante y necesaria de abordar, a fin de evitar caer en reduccionismos o prenociones sobre las "maneras de pensar" de los creyentes evangélicos. Todos estos elementos adquieren una vital importancia para seguirlos trabajando, en un contexto regional en el que las iglesias pentecostales han crecido enormemente a nivel de influencia social y política.

Néstor Da Costa es Doctor en Sociología y Ciencias Políticas y director del Instituto de Sociedad y Religión del Departamento de Humanidades de la Universidad Católica del Uruguay.

”ndacosta@gmail.com.

Valentina Pereira Arena es socióloga y politóloga, doctoranda en Estudios Sociales de América Latina en la Universidad Nacional de Córdoba, Argentina. Es investigadora del Instituto de Sociedad y Religión del Departamento de Humanidades de la Universidad Católica del Uruguay.

$\risingdotseq$ valentina.pear@gmail.com.

Camila Brusoni es estudiante avanzada de la Licenciatura en Sociología de la Universidad de la República (Uruguay). Es investigadora en Servicio Paz y Justicia Uruguay.

$\equiv$ camila.brusoni@gmail.com. 


\section{Referencias}

1. ABRACINSKAS, Lilian; PUYOL, Santiago; IGLESIAS, Nicolás; KREHER, Stefanie. Políticas anti-género en Latinoamérica. Uruguay, el mal ejemplo. Montevideo: MYSU, 2019.

2. AMMERMAN, Nancy. Sacred stories, spiritual tribes: finding religion in everyday life. Nueva York: Oxford University Press, 2014.

3. BERGER, Peter. El dosel sagrado. Para una teoría sociológica de la religión. Buenos Aires: Amorrortu, 1969.

4. BERGER, Peter; LUCKMANN, Thomas. La construcción social de la realidad. Madrid: Amorrortu- Murguía, 1986.

5. CAETANO, Gerardo; GEYMONAT, Roger; GREISING, Carolina; SÁNCHEZ, Alejandro. El Uruguay laico. Montevideo: Penguin Random House Grupo Editorial Uruguay, 2014.

6. CAETANO, Gerardo; GEYMONAT, Roger. La secularización uruguaya (18591919). Montevideo: Taurus, 1997.

7. DA COSTA, Néstor. El catolicismo en una sociedad secularizada: el caso uruguayo. Ciencias Sociales y Religión/Ciências Sociais e Religião, v. 1, n. 1, p. 131-141, 1999. https://doi.org/10.22456/1982-2650.2155

8. DA COSTA, Néstor. La laicidad uruguaya. Archives de sciences sociales des religions, v. 54, n. 146, p.137 - 155, 2009.

9. DA COSTA, Néstor; PEREIRA-ARENA, Valentina; BRUSONI, Camila. Individuos e instituciones: una mirada desde la religiosidad vivida. Sociedad y Religión, v. 29, n. 51, p. 61-92, 2019.

10. FERRE, Zuleika; GERSTENBLÜTH, Mariana; ROSSI, Máximo. Religión y religiosidad en Uruguay. Cuadernos del CLAEH, v. 32, n. 99, p. 19-34, 2009. http://claeh.edu.uy/publicaciones/index.php/cclaeh/article/view/3

11. GUIGOU, Nicolás. El dinero en el proceso de integración y desarrollo de las iglesias pentecostales brasileñas en el Uruguay. Revista Sociedad y Religión, v. 10, n. 11, p. 136-145, 1993.

12. GUIGOU, Nicolás. La nación laica: religión civil y mito-praxis en el Uruguay. Montevideo: Editorial La Gotera, 2003.

13. GUIGOU, Nicolás. Religión y política en el Uruguay. Civitas - Revista de Ciências Sociais, v. 6, n. 2, p. 43-54, 2006. http://dx.doi.org/10.15448/19847289.2006.2.55

14. HALL, David. Lived religion in America: toward a history of practice. Princeton: Princeton University Press, 1997.

15. HORJALES, Rodrigo et al. Religión y pobreza: Ia Iglesia Universal del Reino de Dios en Uruguay. In: ZALPA, Genaro; OFFERDAL, Hans E. (Comps.) iEl reino de 
Dios es de este mundo? El papel ambiguo de las religiones en la lucha contra la pobreza. Bogotá: Siglo del Hombre Editores; CLACSO, 2008.

16. HUGHES, Everett. Cycles, turning points, and careers. In: HUGHES, Everett. Sociological eye. New Brunswick: Transaction Books, 1971.

17. INE- Instituto Nacional de Estadística de Uruguay. Encuesta continua de hogares ampliada, 2006. Flash Temático, n. 6: Religiones, Montevideo: INE, 2006.

18. MALLIMACI, Fortunato; GIMÉNEZ-BELIVEAU, Verónica. Creencias e increencia en el Cono Sur de América. Entre la religiosidad difusa, la pluralización del campo religioso y las relaciones con lo público y lo político. Revista Argentina de Sociología, v. 5, n. 9, p. 44-63, 2007.

19. MÍGUEZ, Daniel. Conversiones religiosas, conversiones seculares. Comparando las estrategias de transformación de identidad en programas de minoridad e iglesias pentecostales. Ciencias Sociales y Religión/Ciências Sociais e Religião, v. 2, n. 2, p. 31-62, 2000. https://doi.org/10.22456/1982-2650.2160

20. ORSI, Robert. The Madonna of 115th street: faith and community in Italian Harlem, 1880-1950. New Haven: Yale University Press, 2002.

21. PRC - Pew Research Center. Religión en América Latina: cambio generalizado en una región históricamente católica, Washington: Pew Research Center, 2014. http://www.pewforum.org/files/2014/11/PEW-RESEARCH-CENTER-ReligioninLatin-America-Overview-SPANISH-TRANSLATION-for-publication-11-13.pdf

22. SOTELO-BOVINO, María Victoria. La búsqueda de la prosperidad económica en las iglesias neopentecostales de Uruguay. Ponencia presentada en el GT 20 del Congreso ALAS, 2015.

Recibido: 12 ago. 2019.

Aceptado: 04 ene. 2020. 